\title{
$\langle S \Delta$ \\ Using the Phenomenological Approach to Explore Integrating the Handicapped into the Nondisabled Society
}

\author{
Lewis S. Aptekar
}

The University of Texas at El Paso

In the bus terminal of Bogota, Colombia, I was solicited by a blind beggar in a wheelchair. From the waist up, he appeared to be a healthy young man of about 30 . He was wearing stylish dark glasses, his hair had been professionally shaped, and he exuded a general air of intelligence and competence. The lower part of his body told a different story. His trousers had been purposely arranged not only to reveal his skinny and deformed legs, but also a plastic tube like those used in hospitals for transfusions. I felt embarrassed as my eyes followed his legs upward. To make things worse, I had the conviction that in spite of his blindness he was seeing my discomfort-a discomfort based in part on what I felt to be my unwholesome need to stare at him. His presence made the confines of the terminal a theater in which I became unwittingly a participant in the human drama of his misfortune. Fortunately, however, his use of such a contrasting costume helped me come to understand how many people react to handicapped persons. These reactions partake of ambivalence. A simple statement of the ambivalence is that one feels both pathos and aversion, both the social duty to aid and succor the unfortunate and the more personal, usually less conscious desire to deny, get away from, or remove a painful image.

Why these less noble feelings? In part, the answer lies in our sensing that we are wounded ourselves. When I encounter a handicapped person it brings to my awareness questions about how I am dealing with my own wholeness, my own imperfections, that I would rather not have to answer. But there is more than that affecting me. I am also reminded that this is an unjust, imperfect, and unpredictable world replete with pain and suffering, ugliness, and brutal accident, in which my well-being is subject to change without notice.

I mention the above incident because the blind beggar had learned to present himself in a way that elicited both facets of my ambivalence. Appropriately, the higher sentiment-social responsibility to help a handicapped person find acceptance and a productive role in society-was represented by the upper part of his body, carefully tended and well dressed. The baser sentiment-disgust and avoidance-came from lower down, from the deformed legs and the evidence of other sufferings he had elected to make public, probably in hopes of being given the pittance that pity and piety prescribe. 
Throughout history, folk literature and mythology have given us two views of the handicapped: as more or better than the average person and as less or worse than human. Thus the ambivalence I felt toward the blind beggar was not just idiosyncratic, not just a modern reaction. Tiresias and Elijah are blind prophets portrayed as wise and virtuous, each ironically endowed with the ability to see the secrets of life and death. "The Maiden without Hands," which Thompson (1946) in his classic book about folktales, calls "one of the eight or ten best known plots in the world," has supernatural powers. The apparently retarded "dummy" in the Grimm fairy tale, The Three Feathers, wins out over his "clever and bright" brothers because he doesn't follow their complex and wordly paths in carrying out their father's directives (Bettelheim, 1977).

Evil in folktales, on the other hand, is often represented by deformed witches or shrunken gnomes whose familiars are animals rather than persons, or by the one-eyed, one-armed, or one-legged pirate or bandit. Often these disabilities seem the result of evil acts, and sometimes they are quite specifically so: Oedipus blinds himself as punishment for the sin of slaying his father and marrying his mother, and for the plague and famine his sins have brought to Thebes.

These literary images indicate that we have for a long time been presented with contrasting information about the disabled. It is no wonder that we approach handicapped persons with ambivalent feelings. The images they evoke in us, and the behavior we exhibit toward them, have depended and will depend on how they are presented or present themselves to us.

Our attitudes and reactions to handicapped persons differ somewhat depending on the nature of the handicap. My basic concern in this article is with the education and rehabilitation of visibly handicapped persons in the institutions where they are cared for. By "visibly handicapped" I mean persons with those handicaps that are in public view.

I have worked in Latin America with several agencies associated with the disabled. ${ }^{1}$ One of the important things I learned there was how handicapped persons can present themselves in such a way as to elicit positive responses from the able-bodied. This has literally kept some handicapped persons alive and even reasonably self-sufficient in a culture where there is little opportunity and even less professional help. The way they cope with the stark realities of their existence can teach us something about our own programs.

Let me illustrate. In Lima, Peru, I encountered two physically disabled beggars. One was without a body below his midsection. While his great arms dragged his torso forward, his head leaned back and his eyes glared into the heavens, a parody of a plea. His begging was 
based in pathos, in asking for pity rather than respect. Like most pitiable objects he repelled the onlookers who might have helped him. Perhaps he reminded them too much of their own secret sins and how those might or should be punished. Perhaps he exemplified the unjustness of fate in a dangerous, brutal world. As I followed him, I verified that he received a few alms. It is discomforting to be faced with the pathetic; it elicits in us rejection or avoidance of the less-than-human.

The second man also had no legs. He was begging as a peddler, selling newspapers at augmented prices, which he asked for as compensation for his disability. He had ingeniously devised a tricycle that he could both pedal and steer with his hands, enabling him to move about the streets at eye level with the pedestrians. Here was no appeal for pity or release from punishment; rather, he elicited images of disability as a test of character to which he had responded with more-than-human competence. He rarely met pedestrians who did not buy the newspapers, and usually they bought eagerly. Why the difference?

Gibbons (1980) notes that the immediate reaction to the disabled is characterized by sympathy or compassion and, at the same time, distaste or aversion. Their "amplification hypothesis" states that there is a level of instability in these interactions that will eventually lead toward movement to one side or the other. Which way the reaction goes, positive or negative, is the result of how the handicapped are perceived by the able-bodied.

In order to make a living, each of these two men developed a persona, an imagistic mask by means of which he sought to direct the responses of the onlooker. We can explain the differences in reactions to each by using the attribution theory of Heider. It suggests that we may attribute an individual's behavior either to things inside of him or her (personal characteristics or dispositions) or to things outside of him or her (situations and circumstances). There is an "attribution bias" which leads us to direct our attention to personal properties and away from environmental determinants (Wright, 1975). Unless handicapped persons can present themselves with a positive image, we are biased to react to them by making assumptions about their personal characteristics-in short, we are poised to blame the victim rather than the situation.

Lerner (1965) presents evidence that people believe there is an appropriate fit between what they do and what happens to them. To quote Novak and Lerner (1968), "If people were not able to believe they could get what they want and avoid what they dislike by performing certain appropriate acts, they would be anxious and, in the extreme, incapacitated. Because of the importance of this belief, the person is continually vulnerable to objective evidence that fate can 
be capricious and beyond one's efforts. This vulnerability becomes important in situations where the person is confronted with someone who has been seriously harmed through no apparent fault of his own" (p. 47). The presence of such a person may elicit the threatening thought, "Can this also happen to me?" Walster's (1966) experiment "tested the hypothesis that an accident victim would be assigned increasing responsibility for his accident as its severity increased. Data supported this hypothesis" (p. 73).

Demonstrating that people are indeed hostile to the handicapped, Katz, Glass, Ludico, and Farber (1977) were able experimentally to induce subjects to shock the handicapped confederates more powerfully than the able-bodied. In order to reduce the dissonance between a fair and an unjust world, the subjects blamed or punished the victims rather than change their point of view about the fairness of fate. This is in line with the attribution bias: Namely, given a cruel act of fate, the observer will blame the victim instead of postulating that the cruel fate came to a worthy person.

The ingenious handicapped peddler with the tricycle had devised an image of competence which made people less fearful of him and therefore less fearful that fate could be randomly destructive. $\mathrm{He}$ was perceived by the able-bodied not as a pitiful person, but as successful in overcoming situational problems. Thus to the able-bodied he was not a potent symbol that fate could be cruel, as was the paraplegic on the ground.

In our country, our ambivalent reactions to the visibly handicapped are made more difficult to understand and therefore accept, because our social codes strongly dispose us to be generous and because we have developed a variety of mechanisms to mute our more negative reactions. However, when we are placed in a face-to-face encounter with visibly handicapped persons, either against our will-as in the case with the beggars above-or because social etiquette demands it; we often feel discomfort. I realized this in the bus terminal when I felt myself pulled in two directions at the same time. I wanted to get away but stayed and stared, as if I was picking at a sore.

Why? On the one hand, we want to flee. Novak and Lerner (1968) hypothesize that handicapped individuals are avoided because they arouse in the observer the thought that they too could acquire a disability. This cruel act of fate violates the person's belief in a just world. In the need to maintain this belief, the handicapped are shunned. The opposite feeling, of staring, can be explained by the "novel stimulus theory" of Langer, Fiske, Taylor, and Chanowitz (1976). This suggests that by staring we try to make the world more predictable. But people are not supposed to stare, especially at the visibly handicapped. So, some of the discomfort we feel in our interactions with the disabled, comes from a conflict between a need to 
satisfy our curiosity and a desire to flee. And, then, further complications arise from our fear at being caught doing either. Over the centuries many cultures have dealt with an aspect of this discomfort through organizing "freak shows" where the social ban on staring is situationally relaxed (Thompson, 1968; Fiedler, 1978). Many of us feel disgust that such shows are permitted, yet the need to stare without constraint persists and the lack of opportunity to do so has created a psychological void.

Contemporary culture in the United States and Canada has developed what some persons consider to be less exploitative ways of dealing with this void. In 1981, in the border cities of El Paso, Texas, and Ciudad Juarez, Mexico, I was involved with a committee planning an event to celebrate the International Year of the Disabled. Despite my reservations, the committee chose wheelchair basketball. At the games, I was both embarrassed to watch handicapped persons exhibiting their disabilities and intrigued that so many persons seemed to enjoy watching. The same can be said of viewing "Special Olympics" which also attracts a large audience.

Part of the attraction of watching, as opposed to participating, may be that in these activities we see handicapped persons doing the same kinds of things we, the able-bodied, do. We watch them not just to compare their performance with that of able-bodied athletes but also as a way to help us deal with the ambivalent tension of staring and avoiding. And we also make another comparison as we watch these "special events": a judgment about how well they are performing, given their handicap, which we compare with our performance, given our private sense of being disabled. It is almost as if we able-bodied spectators want the handicapped to be superhuman so that we can discount their visible signs of being less-than-human. Thus, by trying to make the handicapped seem less unusual we are, as the novel-stimulus theory suggests, making them a part of the world that can be categorized, known, and even identified with.

The ambivalence I've been discussing affects our treatment of the visibly handicapped. We sympathize because we want to, but also because we are supposed to. We may even oversympathize, becoming oversolicitous to compensate for, or cover up, our distaste and aversion.

We are fearful and find ourselves uncomfortable in their presence, staring or seeking to avoid them when we know we shouldn't. We create institutions in which we can hide persons who frighten us, then bring them into the light-through "special" sports events, in TV documentaries, in magazines, or movies-to help us reduce our fear and make our complex reactions more acceptable to us. Frightened by them as they appear to us less-than-human, like the 
crawling beggar, we may welcome the opportunity to see them as more-than-human, like the ingenious tricyclist or the participants in "special" events, at whom we can stare in admiration without shame. By doing this, we turn them into the figures we met in myths and folktales, and avoid treating them as humans, as common folk like ourselves, full of limitations.

In our treatment programs we can either ignore or abuse these cultural predispositions, but I suggest that we learn to take advantage of them. Let me explain what I mean. In Ecuador I worked at two institutions: one a private school for the mentally retarded, the other, a Catholic home for children abandoned by their families and forced in the streets. Both groups were seen as handicapped, the first, because they were unable to function in the world, the second, because they were too much of the world. The people who dealt with them did not realize the power of these metaphors, and the children therefore became victims of the way they were perceived.

At the school for the mentally retarded I saw a class of 10 to 12 -yearold boys and girls playing soccer. They played without vigor as if they were old people, and tried to avoid physical contact with the ball and with each other. Two teachers and their aides, all women, talked amongst themselves while they watched the game. When the boy who had appointed himself goalie was hit by the ball, which happened several times, he ran crying to one of the adults for comfort. Like perpetually worried mothers, these women seemed concerned more with what should be avoided and what might be harmful, than with encouraging the children to participate in the game or joining in it themselves.

At the home for the abandonados, four boys of about the same age as the retarded children had been asked to clean algae out of an ancient swimming pool. Three men stood at the edge of the pool, laughing as the kids undressed in the cool mountain air. The boys and men egged each other on, calling back and forth with jibes and dares. In this generally happy but aggressive confrontation, it seemed to me as if the two groups came closer together in age, the men regaining some of the sense of their youth, the boys emerging into manhood.

It was clear that these two types of children elicited very different responses from the professionals who worked with them. The mentally retarded received maternal care, serious and protective; the abandoned children got brotherly, playful, competitive companionship. Without understanding their complex emotional reactions to these children, the professionals were taken over by the imagery the children evoked and thus reacted to them in the opposite fashion to what they needed. 
I can understand how this happened. When these severely mentally retarded children attempted to reach out and touch me, I recoiled. Then I immediately checked myself, censoring my withdrawal as being morally wrong. From such substitution of morally sanctioned behavior for reactions of disgust may stem overprotection and indulging of the mentally retarded, for the disgust needs a lot of covering-up. But in meeting our own needs to do the right thing, we too often fail to meet the real needs of the mentally retarded.

When I mingled with the abandonados, I admired their bravado and their adventurous lives, though I pitied them because they were homeless. Nevertheless, I found myself wanting to play with them, as I did with my first tough friend when I thought I was a tough boy. My wishful adult memories of a never-to-be-relived nor ever fully indulged wildness was as self-deceptive an overreaction of the mentally retarded, and equally could have led to a failure to appreciate and deal with the real needs of these children.

Treatment for the handicapped is made complex by our needs to resolve the ambivalent reactions we have toward them. The often subconscious and probably universal feeling we have of being ourselves wounded, and thus, in a way, handicapped, is a very powerful motivating force in determining the nature of the interchange between the able-bodied and the handicapped. Accompanying this is an equally strong but usually more conscious sense that we should succor the wounded. Then, too, there is the problem of what to do with negative feelings. "While people may feel ambivalent about stigmatized persons, they also feel guilty about the negative attitudes they hold and are usually reluctant to express those attitudes" (Gibbons, 1980, p. 593). Those of us who help handicapped persons are, even if we do not consciously feel it, helping ourselves-either by dealing with our own wounds through identifying with the pain of those we set out to help, or by making ourselves more acceptable to ourselves by putting salve on the unwanted but powerful negative reactions to people affected by tragic events.

Problems may arise for persons whose awareness of these reactions is inaccessible or nonexistent. Unable to put distance and separation between their less noble feelings and the patients or pupils or clients with whom they work, they may, as a way of controlling these emotions, develop smothering relationships with those they try to help. Guggenbuhl-Craig (1979) calls these persons "wounded healers." Rusalem and Malikan (1968) identify similar behavior on the part of caretakers as "authoritarian virtuousness," and describe it as stemming from a need to help others because of the inability to help oneself. Carver, Glass, and Katz (1978), and Carver, Glass, Snyder, and Katz (1977) describe the "sympathy effect," through which able-bodied people adopt overly positive stances toward the disabled in order to compensate for their guilt about their negative 
attitudes. Whatever we want to call it, persons working within these styles will generate dependence and hinder the development of independence on the part of their charges. These attitudes are not uncommon; in fact, the images the handicapped project and our own predispositions to respond in ambivalent ways elicit them to some degree in all of us.

At both of the Ecuadorian institutions I've mentioned, it seemed to me that the adults were unwittingly acting out these behaviors. The mentally retarded children lived in symbiotic dependence with their benefactors, clinging to childhood and detached from the complex adult world. The abandonados were controlled by and dependent on men trying to recapture their youth by identifying with the boys, whose pranks and daring were fostered by these men. The boys seemed in need of some of the maternal protection the mentally retarded got too much of; the mentally retarded seemed in need of a program that would aid them to be more aggressive, more youthful and vital, more like the abandonados.

\section{What Praxis is Needed?}

The problems presented by the sympathy effect, by wounded healers, and by virtuous authoritarians are among many that arise when persons charged with caring for the handicapped are ignorant of how less-than-conscious images control their reactions and behaviors.

How much are they (and we) aware of the "blame the victim" attribution arising from our unconscious wish or fear that a handicap is a punishment for wrongdoing, as in reactions to the crawling beggar with his glaring appeal to heaven? How aware are we of wanting to overprotect people as compensation for our unacceptable desire to avoid them, as in the Ecuadorian school for the mentally retarded? How much do we try to hide the handicapped from the world because we ourselves do not wish to see them, then arrange to watch the wheelchair basketball or special olympics to deal with our need and guilt about wanting to stare at them?

We must recognize our own ambivalences and in so doing comprehend the genesis and the complexity of our reaction. But this is only a prelude to the difficult job of helping the handicapped understand and make productive use of the kinds of images they elicit in others.

Can we, for instance, teach handicapped persons how to present themselves as positively as did the legless beggar peddling newspapers from his tricycle? One group of severely retarded adolescents I saw in Columbia was involved in a program that consciously tried to manipulate the reactions of potential benefactors by teaching these adolescents to present themselves so that they would not just 
elicit overprotective responses. The young man who was their teacher arranged for each child to have a small parcel of land to dig up and plant with vegetables. He had them march to and from their field in military fashion, chanting somos agricultores (we are farmers). Each had some unsightly mannerism: One drooled saliva, another had twitching arms, the eyes of others moved randomly. However, because they had to march in formation and with good posture, they presented an image of competent self-esteem rather than feebleminded inadequacy, and I found myself looking at them and shaking hands with them without recoiling, realizing that instead of avoiding or overindulging them, I was seeing them as competent persons worthy of engagement.

With all handicapped people, we are faced with a situation which puts into question our sense of morality as caring and responsible persons who are facing tragedy. Each time the encounter occurs, we are asked to rethink our notions about what is too little and what is enough, a kind of test of our character that we tend to avoid and be attracted to at the same time.

We know that the difference between them and us is only temporary, that at any time we too can become blinded, lamed, mentally incompetent. The temporary wholeness we feel is made fragile and precarious when we encounter handicapped people. We are, at some level, always different; at the least, we feel different in comparison to others. Thus, our uncertainty about our way of dealing with our wounds and our limitations is placed in front of us to be compared and judged.

We must be reminded that the disability is more than the actual handicap-it is also a mythical character trait, an affirmation or negation of moral quality for both the possessor of the disability and for those who choose to interact with the disabled. Government policy, clinical treatment, or educational programs will ultimately fail to help handicapped persons be seen as fully human if they do not take into account the power of imagery to penetrate into our sense of ourselves and the power of the moral associations that we have inherited through our mythic and literary tradition.

To neutralize the imagery of the handicapped in sheltered workshops excludes them from our world. To allow the handicapped to beg for assistance in ways that elicit images we wish to avoid not only endangers their integrity but affronts our sense of morality. The handicapped can, however, be helped to do what all of usthey, their benefactors, ourselves as able-bodied onlookers-must do. That is, to confront honestly the ambivalence that is part of all our reactions to the handicapped and inherent in all of our experiences with them. 


\section{Note}

1. In 1981, The International Year of the Disabled, I was a representative of the United Nations in South America. In that capacity, I encountered many handicapped persons and visited several programs for the disabled. Since then I have returned to South America as a Fulbright Scholar. Many of the anecdotes in this article are taken from these experiences.

\section{References}

Bettelheim, B. (1977). The uses of enchantment: The meaning and importance of fairy tales. New York: Vintage.

Carver, C.S., Glass, D.C., \& Katz, I. (1978). Favorable evaluations of blacks and the handicapped: Positive prejudice, unconscious denial or social desirability? Journal of Applied Social Psychology, 8, 97-106.

Carver, C.S., Glass, D.C., Snyder, M.L., \& Katz, I. (1977). Favorable evaluations of stigmatized others. Personality and Social Psychology Bulletin, 3 , 232-235.

Fiedler, L.A. (1978). Freaks: Myths and images of the secret self. New York: Simon and Schuster.

Gibbons, F. (1980). Reactions to stigmatized others: Response amplifications vs. sympathy. Journal of Experimental Social Psychology, 16, 591-608.

Guggenbuhl-Craig, A. (1979). Power in the helping professions. Dallas: Spring Publications.

Katz, I., Glass, D.C., Ludico, D., \& Farber, J. (1977). Ambivalence, guilt, and the denigration of a physically handicapped victim. Journal of Personality, 45, 419-429.

Langer, E.L., Fiske, S., Taylor, S.F., \& Chanowitz, B. (1976). Stigma, staring, and discomfort: A novel stimulus hypothesis. Journal of Experimental Social Psychology, 12, 451-463.

Lerner, M.J. (1965). Evaluation of performance as a function of performer's reward and attractiveness. Journal of Personality and Social Psychology, 1, 335-360.

Novak, D.W., \& Lerner, M.J. (1968). Rejection as a consequence of perceived similarity. Journal of Personality and Social Psychology, 9(2), 147-152.

Rusalem, H., \& Malikin, D. (1968). Contemporary vocational rehabilitation. New York: University Press.

Thompson, C.J.S. (1968). The mystery and lore of monsters. New York: University Books.

Thompson, S. (1946). The folktale (121). New York: Dryder.

Walster, E. (1966). Assignment of responsibility for an accident. Journal of Personality and Social Psychology, 3, 73-79.

Wright, B. (1975). Social-psychological leads to enhance rehabilitation effectiveness. Rehabilitation Counseling Bulletin, 214-223. 